\title{
The dawn of chelonian research : Turtles between comparative anatomy and embryology in the 19th century
}

\section{MacCord, Kate}

2015

MacCord, K, Caniglia, G, Moustakas-Verho , J \& Burke , A 2015, ' The dawn of chelonian research : Turtles between comparative anatomy and embryology in the 19th century ' ,

Journal of Experimental Zoology. Part B: Molecular and Developmental Evolution, vol. 324 , no. 3 , 22587 , pp. 169-180 . https://doi.org/10.1002/jez.b.22587

http://hdl.handle.net/10138/223805

https://doi.org/10.1002/jez.b.22587

acceptedVersion

Downloaded from Helda, University of Helsinki institutional repository.

This is an electronic reprint of the original article.

This reprint may differ from the original in pagination and typographic detail.

Please cite the original version. 


\section{The Dawn of Chelonian Research:} Turtles Between Comparative Anatomy and Embryology in the 19th Century

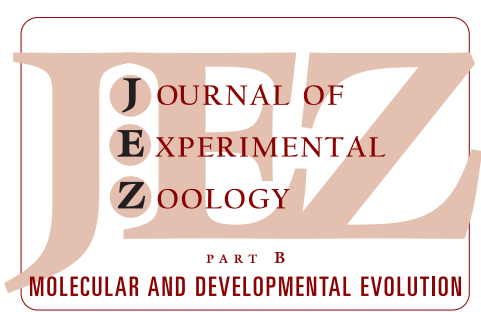

KATE MACCORD $^{1 *}$, GUIDO CANIGLIA ${ }^{1}$, JACQUELINE E. MOUSTAKAS-VERHO ${ }^{2}$, AND ANN C. BURKE ${ }^{3}$

${ }^{1}$ Center for Biology and Society, Arizona State University, Tempe, Arizona

${ }^{2}$ Institute of Biotechnology, University of Helsinki, Helsinki, Finland

${ }^{3}$ Department of Biology, Wesleyan University, Middletown, Connecticut

\begin{tabular}{ll} 
ABSTRACT & Many evo-devo studies of the turtle's shell draw hypotheses and support from historical sources. \\
The groundbreaking works of Cuvier, Geoffroy St. Hilaire, Carus, Rathke, Owen, and others are being \\
revived in modern research, and their centuries-old understanding of the turtle's shell reconsidered. \\
In the works of these eminent biologists of the 19th century, comparative anatomy and embryology \\
of turtle morphology set the stage for future studies in developmental biology, histology, and \\
paleontology. Given the impact that these works still make on modern research, it is important to \\
develop a thorough appreciation of previous authors, regarding how they arrived at their \\
conclusions (i.e., what counted as evidence?), whether there was debate amongst these authors \\
about shell development (i.e., what counted as an adequate explanation?), and even why these men, \\
some of the most powerful and influential thinkers and anatomists of their day, were concerned \\
with turtles. By tracing and exposing the context and content of turtle shell studies in history, our \\
aim is to inform modern debates about the evolution and development of the turtle's shell. J. Exp. \\
Jool. (Mol. Dev. Evol.) 324B:169-180, 2015. @ 2014 Wiley Periodicals, Inc. \\
$\begin{array}{l}\text { J. Exp. Zool. } \\
\text { (Mol. Dev. Evol.) } \\
\text { 324B:169-180, } \\
\text { 2014 } \\
\text { of chelonian research: Turtles between comparative anatomy and embryology in the 19th } \\
\text { century. J. Exp. Zool. (Mol. Dev. Evol.) 324B:169-180. }\end{array}$ \\
\hline
\end{tabular}

It is striking that the questions and problems that scientists address today when dealing with the development and evolution of the turtle shell are the same as the ones that Georges Cuvier (17691832), Étienne Geoffroy Saint-Hilaire (1772-1844), Martin Rathke (1793-1860), and Richard Owen (1804-1892) addressed in their seminal works on Chelonians almost two centuries ago. Debates over the construction of the turtle's shell, even questions as seemingly straightforward as whether the carapace and plastron are endoskeletal or exoskeletal, are still a matter of debate today. It is still hard to find a consensus, despite advances in technology, access to specimens, and the boom of big data that accompanies modern biology (Zangerl, '39; Gilbert et al., 2001; Cebra-Thomas et al., 2005; Scheyer et al., 2007; Moustakas, 2008; Hirasawa et al., 2013; Rieppel, 2013). In this article, we go back to the historical roots of current debates. We expose how, although the questions and main hypotheses mostly stayed the same over the course of two centuries, changing metaphysical and epistemological assumptions shaped and redirected the field of Chelonian studies. We focus mostly on an important and fundamental shift in the investigation of turtle's shell; the transition from anatomical

\footnotetext{
Grant sponsor: Academy of Finland.

* Correspondence to: Kate MacCord, Center for Biology and Society, Arizona State University, P.0. Box 873301, Tempe, AZ 85287-3301.

E-mail: kmaccord@asu.edu

Received 21 March 2014; Accepted 18 June 2014

DOI: 10.1002/jez.b.22587

Published online 30 July 2014 in Wiley Online Library

(wileyonlinelibrary.com).
} 
and morphological observations, such as Cuvier's and Geoffroy's works, to embryological and developmental studies of turtle morphology, in particular Rathke's and Owen's investigations.

Cuvier's Regne Animal (originally published in 1817; English translation published in 1854), Rathke's “Über die Entwicklung der Schildkröten” (1848) or Owen's “On the Development and Homologies of the Carapace and Plastron of the Chelonian Reptiles" (1849) are commonly referred to as seminal works for our understanding of the turtle's shell. Given the permanence of the main hypotheses and questions about the nature of the turtle shell and the homologies of its parts, it is no surprise that recent studies on Chelonians have made increasing use of historical texts to refine hypotheses, organize explanations, and provide interpretations of new experimental data (Gilbert et al., 2001; CebraThomas et al., 2005; Scheyer et al., 2007, 2008; Moustakas, 2008; Hirasawa et al., 2013; Lyson et al., 2013a). Many recent articles still refer to Cuvier's hypothesis of the endoskeletal origins of the turtle shell (1799, 1819), Carus' mixed hypothesis (1834), and Rathke's detailed embryological investigations (1848).

In a pivotal piece for the resurgence of interest in the development and evolution of the turtle shell, Burke ('89) focused on the altered relationship between the axial and appendicular skeleton. Burke identified the carapacial ridge (CR) as the site of an epithelial-mesenchymal interaction that initiates carapace development and hypothesized that this common developmental mechanism plays a critical role in both the development and evolution of the unique turtle body plan. The rearrangement of the primary skeletal elements is seen as the prerequisite for subsequent evolution including the highly variable levels of dermal ossification seen across all turtle taxa. The debate regarding the nature of the ossifications in the shell was revived in a 2001 article from Scott Gilbert, Ann Burke and colleagues, and is reiterated throughout the more recent works from the labs and colleagues of Torsten Scheyer (Scheyer et al., 2007), Tyler Lyson (Lyson et al., 2013a), and Shigeru Kuratani (Hirasawa et al., 2013). This last article reports on the main hypotheses produced in the early history of chelonian studies about the endoskeletal or exoskeletal origins of the turtle shell, as well as about the evolutionary implications of such hypotheses. The terms exo- and endoskeletal are positionally defined, and somewhat anachronistic in the absence of new molecular characters. The use of "endoskeleton" in particular risks a confusion of placement with process. The ossification of intramembranous or dermal bones is histologically distinct from endochondral ossification, and the endoskeleton should not be confused with the endochondral skeleton.

In our article, the focus is on the shift from investigations of adult specimens to studies of embryos within the historical turtle literature. This shift occurred in the context of a larger movement of epistemic values, away from explanations that sought accurate depictions of a natural order and towards explanations that valued mechanistic and testable hypotheses. We start with French functionalism and structuralism and look into Cuvier's and
Geoffroy's ideas about turtle morphology. Both Cuvier and Geoffroy relied on anatomical evidence gathered from adult specimens to construct both their investigations of turtles and their larger worldviews. Despite their shared opinion of the nature of the carapace, these two preeminent scientists drew their conclusions from vastly different epistemological and metaphysical assumptions about classification and the nature of morphologies. Embryological works from the mid 19th century represent an important shift in early understanding of the turtle's morphology. These works sought to test hypotheses about morphologies by comparing their development across embryos and taxa. In the works of Rathke (1847) and Owen (1849a), the nature of turtle morphology is discussed at the level of the embryonic development of morphological characters. Since then, explanations of the turtle's puzzling morphology have increasingly relied on the understanding of the developmental mechanisms that underpin the emergence of this peculiar morphology. The detailed understanding of embryonic development radically changed the way the developmental and evolutionary origins of turtle morphology were investigated because it allowed scientists to garner a wider range of evidence and test hypotheses about the diversity and relationships of morphology across taxa.

\section{CUVIER, GEOFFROY, AND CARUS: FUNCTIONALISM,} STRUCTURALISM, AND TRANSCENDENTAL MORPHOLOGY Georges Cuvier and Étienne Geoffroy Saint-Hilaire (henceforth, "Geoffroy") were two of the most prominent and influential anatomists in France at the turn of the nineteenth century. Their works influenced generations of anatomists, and their infamous debate that erupted in l'Académie des Sciences in Paris in 1830 over form versus function highlighted a growing division within the natural sciences that would have repercussions for the development and progress of evolutionary morphology and embryology for years to come. Each of these men, in addition to their expansive works on comparative anatomy throughout the animal kingdom, studied and published on the classification and anatomy of the turtles. We will see that in spite of grossly different understandings of what underlies a rational system of taxonomy and what principles should guide comparative anatomy, both Cuvier and Geoffroy came to very similar conclusions about the development of the carapace and plastron.

Cuvier's Functionalist Perspective on Turtles

Georges Cuvier (1769-1832) was a French naturalist and zoologist, and professor at the Muśeum National d'Histoire Naturelle. Building upon his predecessors, like Comte de Buffon and Comte de Lacépède, Cuvier sought to systematically understand the natural order of the world. Whereas naturalists before Cuvier had largely divided the animal kingdom into two main groups (vertebrates and invertebrates), Cuvier envisioned four principle divisions, called embranchements (Vertebrata, 
Mollusca, Articulata, and Radiata). Cuvier placed the turtles into his third class of Vertebrata, called "Reptilia," which presented "more varied forms, characters, and modes of gait (Cuvier et al., 1854; 267)" than either of the preceding classes (Mammals and Aves). As Cuvier put it, when it came to Reptiles, "Nature seems to have tried to imagine grotesque forms, and to have modified every possible way the general plan adopted for all vertebrate animals (Cuvier et al., 1854; 267)." Within the Reptilia, the first order of organisms were the Chelonians, "the body of which, supported by four limbs, is enveloped by two plates or bucklers formed of the ribs and sternum (Cuvier et al., 1854; 268)." Cuvier describes the order as follows:

These animals are distinguished, at the first glance, by the double buckler in which their body is inclosed, and which only allows the head and neck, the tail and the four limbs, to be protruded. The upper buckler, termed the carapace or shield, is formed by the ribs, in number eight pairs, which are widened and joined together, and also to the plates adhering to the annular portion of the dorsal vertebrae, by dentelated sutures, so that the whole is completely deprived of mobility. The inferior buckler, named the plastron or breast-plate, is formed of pieces which represent the sternum, and which are ordinarily nine in number. A frame-work composed of bony pieces, which are believed to have some analogy to the sternal or cartilaginous portion of ribs, and which in one subgenus even remains cartilaginous, surrounds the carapace, and unites all the ribs which compose it. These two bony envelopes are immediately covered by the skin, or by scales; the scapula, and all the muscles of the arm and neck, instead of being attached to the ribs and spine, as in other animals, are all underneath, as are also even the bones of the pelvis and the muscles of the thigh; so that, in this respect, a Tortoise may be regarded as an animal turned inside-out. (Cuvier et al., 1854; 269)

Cuvier further divided the Chelonians (or "Tortoises" as he more commonly calls them) into five subgenera, "principally after the form and tegument of their carapaces and feet (Cuvier et al., 1854; 270)." The five genera (Land tortoises, Emydes or Freshwater Tortoises, Turtles, Chelydes [modern day Chelydra] and Soft Tortoises) included a variable number of species.

Cuvier's embranchements implied an existence of gaps in the natural order that his predecessors were wont to acknowledge. The embranchements were independent, natural kinds, and above all, were modes of functional organization, not distinct structural patterns (Winsor, '76; Amundson, 2005). For instance, features shared by members of a given embranchement only reflected a shared functional need: "This correspondence of general forms, which results from the arrangements of the organs of motion, the distribution of the nervous masses, and the energy of the circulating system, should serve then for the basis of the primary sections to be made in the animal kingdom (Cuvier et al., 1854; 32)." To Cuvier, then, organismal form was bestowed by functional necessity-a rationale that led him to some highly teleological explanations.

Cuvier's descriptions of turtles are best understood in light of his teleological framework. Without knowledge of his functionalist mindset, when Cuvier writes about the entrapment of the turtle's body within a "double buckler" a reader may be led to believe that Cuvier is using the term buckler as a simple description of the shell's appearance. However, Cuvier's use is more metaphorical-a buckler is a small, round shield used to defend against hand-tohand combat-and it is largely the protective, shielding function of the shell to which Cuvier is alluding.

These two protective bucklers, according to Cuvier, are found in all members of the Chelonian order, implying that the protective function is preserved throughout the taxon, and in some sense is the defining feature of the taxon. Although Cuvier does not lay out in detail his methods or evidence for his natural order, he does tell the reader that he attempted to dissect at least one member of each subgenus (Cuvier et al., 1854; 4). The point of anatomy to Cuvier was not to provide an abundance of details about the structure of any particular organism (his writing was highly economical), but to provide the most expansive and comprehensive overview of nature. This vantage of the natural order was thus accrued through a methodological commitment to a broad, conservative empiricism, which, when combined with his quest for economy of detail, led him to search for common characters within the variation surrounding him. For turtles, the most identifiable common element was the shell, which Cuvier believed to be entirely of endoskeletal origin (i.e., from the ribs). Thus, when Cuvier writes about the endoskeletal nature of the turtle's shell, he has created a broad generalization of the order, constructed out of a few dissections of adult organisms, and without reference to their development.

Cuvier's functionally defined embranchements were also the result of his attempt to understand the structures of animals as products of environments and conditions (both external and internal). Cuvier's focus on the organismal environment led him to formulate two main principles through which the appearance, existence, and natural order of animals could be understood: the "principle of conditions of existence" and the "principle of the correlation of parts." The former tells us that the parts that constitute the organism must be in harmony with the animal's environment and mode of life. Under this principle, an organism's anatomy is defined by its ability to function in a given environment. For example, when Cuvier describes the Emydes, he tells us that they "have no other constant characters to distinguish them from the preceding [land tortoises], beyond the further separation of their toes... The structure of their feet adapts them to more aquatic habits (Cuvier et al., 1854; 412).” Thus, for the Emydes, the functionality required for living within an aquatic environment conferred a particular foot structure, which in turn distinguished it from others in the Chelonian order. 
The principle of correlation of parts moved the focus inward, and tells us that in order for an organism to be working and viable, functional relationships must exist between the parts. It was with this principle in mind that Cuvier believed that he could reconstruct an organism in its entirety from a single bone (see Rudwick, 2008). This principle came with a corollary, the "principle of subordination of characters," which established a hierarchical ranking of parts and systems within organisms. Cuvier's hierarchy of systems internalized his principle of conditions of existence by ranking systems based on what he believed to be most fundamental for life. To Cuvier, the most fundamental of organ systems was the nervous system (followed by the circulatory and respiratory systems), and it was upon the nervous system that he primarily defined his embranchements. It is telling that in his Regne Animal (1817; English translation published in 1854), Cuvier begins his description of every order by briefly addressing their most important systems-for Chelonians, Cuvier begins with a description of the heart, circulatory system and then lungs (see Cuvier et al., 1854; 269), the order of the systems denoting their relative importance in his anatomical scheme.

Because function was the basis upon which Cuvier built his natural order, and, because he believed that structures were determined purely by the functional commitments of a given system, Cuvier came to the conclusion that species were immutable, fixed entities. Variation within a species was governed by the functional adequacy of the system in question (principle of correlation of parts), and the capacity of that system to allow the organism to function within the external environment (principle of condition for existence). Thus, to Cuvier, any organism that could exist (in a functional sense) did exist.

And, because Cuvier's natural order was built upon unchanging, immutable entities defined by their functional adequacy (and not their relationships to each other), he also adopted a system of taxonomic nominalism in which he viewed anything above the category of species as having no independent reality (i.e., taxa like genus, order, class were arbitrary). While Cuvier employed taxonomic categories above the species level, he did not believe that they reflected natural kinds. Thus, “... the data are always about individual species, not about real relations between species, and certainly not about taxonomic entities such as genera and families (Amundson, 2005; 43)."

Cuvier's commitment to taxonomic nominalism, that is, the understanding that taxonomic categories do not have a biological reality, is evident in his description of the Chelonia, where divisions are based on minimal descriptions of characters, as is evidenced in his description of the "leatherbacks": "Those species which have no scales, but the carapace of which is invested with a sort of leather." For some genera, Cuvier includes brief descriptions of individual species with which he was familiar. For instance, within the "Soft Tortoises," Cuvier places the Trionyx of the Nile turtle (now: T. triunguis), and describes them thus: “... is sometimes three feet long and of a green colour spotted with white; the carapace by slightly convex. It devours the young Crocodiles as soon as they are excluded, and thus renders more service to Egyptians than even the Mangoste [mongoose] (Cuvier et al., 1854; 272)."

When it came to the carapace and plastron, Cuvier was just as economical in detail as with all of his other descriptions. From the quotation given at the opening of this section it is evident that Cuvier believed both the carapace and the plastron to be endoskeletal in nature, and simply structures which were derived from the ribs and vertebrae (carapace) and sternum (plastron). This conclusion about the formation of the carapace and plastron is the same that Cuvier had given in his (1800) text, Leçons d'anatomie comparée. No further explanation or information about these structures is given, but it is clear from his description that Cuvier believed these bodily modifications to contribute a structural stability and protection to the organism.

\section{Geoffroy's Structuralist Perspective on Turtles}

Geoffroy largely concurred with Cuvier's opinion of the shell. For him, the plastron in all turtles started from nine ossification points that enlarged and gave rise to one structure. The plastron was analogous to the sternum, and thus an endoskeletal structure. Regarding the carapace, Geoffroy agreed with Cuvier about the origins of the neural plates from vertebral elements, and more broadly about the endoskeletal origins of the carapace. While Cuvier and Geoffroy reached a general agreement about the endoskeletal origins of the turtle's shell, they arrived at their conclusions from vastly different perspectives such that we will now outline Geoffroy's understanding of what principles underlie the organization of organismal form.

During the period in which Geoffroy worked, functionalism (the understanding of nature in which function dictated form) was widely accepted as the most rational basis upon which to describe nature. This worldview drew from the Newtonian framework in which the search for causes was subordinated to the task of giving accurate descriptions of natural phenomena. For functionalists, to say that a structure, or importantly a system, worked in a given capacity was an adequate description of the natural order and its causes. However, not everyone viewed the description of functions as a sufficient way to understand the world. Some, like Geoffroy (1772-1844), a professor at the Muśeum National d'Histoire Naturelle, noticed that there was not a one-to-one correspondence between form and function. In 1807, Geoffroy delivered his "First Memoir on the Fishes," in which he identified the furcula in fish (a bone specifically identified by functionalists, most notably Cuvier, to be restricted to birds as a part of their system for flight). Geoffroy's search for correspondences between bones and structures among different species (what we now think of as homology) was a distinct and very important break with the conservative empirical tradition of functionalist anatomists like Cuvier. 
Why was this break so important? By shifting the focus away from function as the basis of organismal form, Geoffroy forced future anatomists to think about what, if not function, could be the basis for similarities and differences between organisms. Geoffroy, and anatomists directly after him, dealt with this issue in different ways, but all tended to abstract from their studies of comparative anatomy towards the reconstruction of a generalized vertebrate anatomy. This process of abstraction flew in the face of the strongly empirical tradition employed by Cuvier and contemporary anatomists. The process of abstraction from observation to theory became a core component in a new worldview about what caused organismal form-transcendental morphology.

Geoffroy's explication of transcendental morphology (and consequent rejection of functionalism) occurred gradually. During the early years of his career, Geoffroy collaborated with Cuvier on a series of five memoirs that detailed everything from the classification of mammals to the natural history of orangutans (see Appel, '87; 32, for details). After a series of scientific expeditions under Napoleon, Geoffroy returned to Paris and began to workout in earnest a unified biological worldview that he had hinted at in previous work. Geoffroy developed a view, commonly referred to as the "Unity of Plan," which can most aptly be described as an attempt to understand the basis of organic composition. To Geoffroy's trained anatomist's eye, nature was composed of organisms that shared, in principle, a common construction plan, but varied in accessory parts. This understanding is revealed in Geoffroy's "Principle of connections" in which the primary goal was not to define the form or the function of specific parts, but to determine the relationships between parts. It was through observing the relationships between the parts, Geoffroy thought, that the Unity of Plan could be understood and used to classify taxonomic relationships between groups.

Geoffroy's philosophical anatomy and incipient rejection of Cuvier's functionalism is evident in his memoir on soft-shelled turtles from 1809 ("Memoire sur les Tortues molles”), over a decade ahead of his official break with Cuvier. Geoffroy begins this short treatise by defining the soft-shelled turtle as a new taxon. Here, Geoffroy ponders the absence of the bony elements of the carapace: "It is such an important anomaly to see a carapace that does not participate in the solidity that this structure usually possesses, given that this characteristic usually provides protection to the carapace, therefore the author examines whether this difference has something essential in the organization (GeoffroySt-Hilaire, 1809; 363-emphasis is ours)." This is a telling passage for two reasons. First, there is an implicit critique of functionalism -Geoffroy is questioning the reasoning that if the function of the carapace is protection, how is it possible that soft-shelled variety can exist? Second, Geoffroy hints at what will become the underlying principle for his philosophical anatomy-the organization of the organism is more important than the functions of its parts. This principle Geoffroy later turned into the Principle of Connections.
During the early years of Geoffroy's development of the Unity of Plan concept, Cuvier did not adamantly oppose his work. After all, the principle of connections was not inconsistent with Cuvier's own views, especially his Principle of Correlation of Parts. It was only in 1820 when Geoffroy suggested that the common plan of vertebrates was applicable to insects (i.e., that the endoskeleton of vertebrates was based on the same architecture as the exoskeleton of insects and crustaceans) that the break between Cuvier and Geoffroy, and thus the hardening of worldviews between functionalists and structuralists (or, here, transcendental morphologists) began (Appel, '87). While Cuvier had been willing to overlook methodological and some philosophical differences, Geoffroy's expansion of his Unity of Plan from vertebrates to insects violated Cuvier's embranchements and subsequently undermined his entire natural framework.

Despite these fundamental differences, Cuvier and Geoffroy held similar views on the nature of the turtle's shell-each believed that both the plastron and carapace was derived from the endoskeleton. And, although the pair reached similar conclusions, used a similar methodology and sample set, their works on turtles were put to very different means. Cuvier and Geoffroy were both interested in constructing grand classificatory schemes and in this way, assembling an understanding of the ways in which species relate to one another. Their works on turtles were contributions to these ends-constructing broad worldviews of Nature. As we have seen, Cuvier and Geoffroy ultimately held very different opinions about what underlies a rational system of nature, and thus, their works on turtles were incorporated into vastly different metaphysical systems.

Turtles in Naturphilosophie, the Urtyp, and the "Mixed Hypothesis" Meanwhile, across the Rhine, a different form of transcendental morphology, heavily rooted in the German philosophical tradition derived from Kant, arose. This tradition, called Naturphilosophie, shared many ideas with Geoffroy's structuralist philosophy-both were focused on uncovering the basis for the underlying similarities seen in organismal form, and looked to structural, rather than functional, relationships for support and evidence. Whereas Geoffroy's Unity of Plan was an attempt to understand the organization and relations of organismal form, for the Naturphilosophen, Nature represented a single all-embracing unity, a fundamental unit of matter, process and spirit, and the object of their philosophy of nature was to establish the unfolding of the inorganic, organic, and ultimately the social and moral realms. Thus, the Naturphilosophen were invested in the "Unity of Nature." Much like Cuvier's functionalist framing of Nature, the anatomical treatises produced within Naturphilosophie espoused a highly teleological understanding of nature. It is in this tradition that Carl Gustav Carus (1789-1869) falls.

Carus was a noted physician, psychologist (whose works heavily influenced Carl Jung), and painter, whose fascination with 


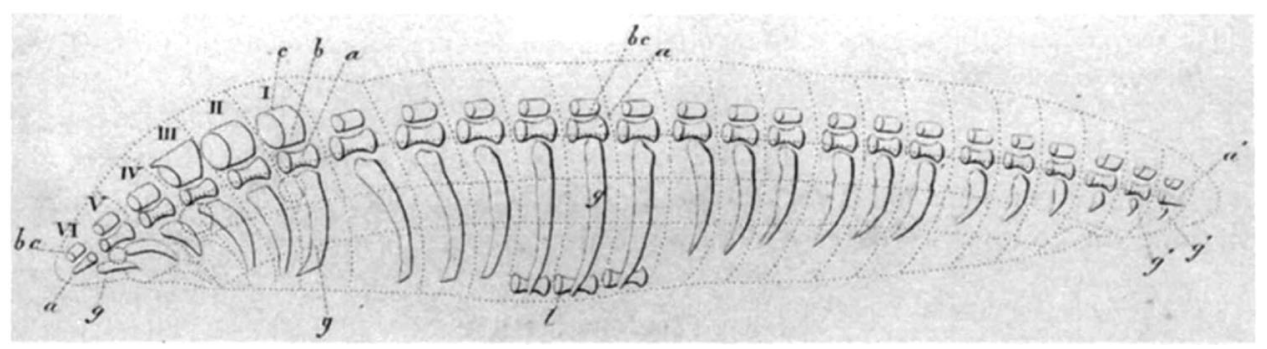

Figure 1. Carus' diagram of the simplest vertebrate skeleton, the Urtyp. From Carus, 1828; Table IV, Figure 1.

nature led him to publish broadly on everything from circulation in insects to a handbook of zoology. Carus, like his contemporaries Oken and Goethe, was heavily invested in understanding the Unity of Nature. His approach was almost purely deductive-Carus attempted to transcend empirical reality in order to mentally constitute the unifying principles of natural phenomena (see Lenoir, ' 81 for a comprehensive examination of Naturphilosophen and the deductive reasoning of Carus). That is not to say that he had no hands-on contact with nature or anatomical specimenshe did-but his understanding of nature was such that the observable entities in front of him were only indications of a greater plan.

This greater plan led Carus to develop the Urtyp concept (Fig. 1) -most will be more familiar with Richard Owen's later "archetype" concept, which we will address in short order (Carus, 1828). For Carus, the Urtyp signified the simplest schema of possible vertebrate anatomy. From this simplest schema, an organized, more complex body had to be mentally constructed by the differentiation of the simplest parts. Carus' mixed hypothesis (e.g. the carapace was comprised of both endoskeletal and exoskeletal portions) about the origins of the turtle's carapace must be understood in light of his Urtyp concept. In the first edition of his work, Carus understands the costal plates of the carapace to be incredibly expanded transverse vertebral processes (Carus, 1827). Here, Carus is imagining the derivation of the simple Urtyp by expansion of a vertebral element. For Carus, this is not a developmental hypothesis (i.e., he does not think that embryological evidence is suited to answer this question because his methods are strictly deductive). By the second edition (see Owen, 1849a for a discussion of Carus' change) Carus has changed his mind on the nature of the bones of the carapace. Instead of being expanded transverse processes, the carapacial bones are now a mix of dermal skeleton and endoskeleton-the plates begin their development as dermal connective tissue and some coalesce with the spines of subadjacent vertebrae (these are the endoskeletal plates) while others simply ossify (these are the exoskeletal plates). This notion is not explained in detail, but Carus attributes the process to the disappearance of spinous processes in turtles, and a concomitant replacement of them with the vertebral bodies. Essentially, Carus inverted the standard anatomy of the vertebra in order to constitute turtle anatomy-something for which there continues to be no evidence or support.

In order to construct the Urtyp, Carus relied heavily on his sense of aesthetics-he mentally abstracted the "simplest schema" from the diversity of forms surrounding him. His task, then, was to also mentally reconstruct the transformation from this simple schema, or Urtyp, back into a set of organismal forms. It was this kind of speculative, aesthetic approach to organismal form that led Carus in 1827 to declare the thorax of the tortoise to be a "more perfect development of the ribless and imperfect thorax of the frog (Carus, 1827; 147)" (see Fig. 2 for a modern approximation of Carus' views).

\section{RATHKE AND OWEN: STRUCTURALISM, COMPARATIVE ANATOMY, AND EMBRYOLOGY}

Naturphilosophie received considerable pushback with the rise of classical embryology. On the continent, scientists like Christian

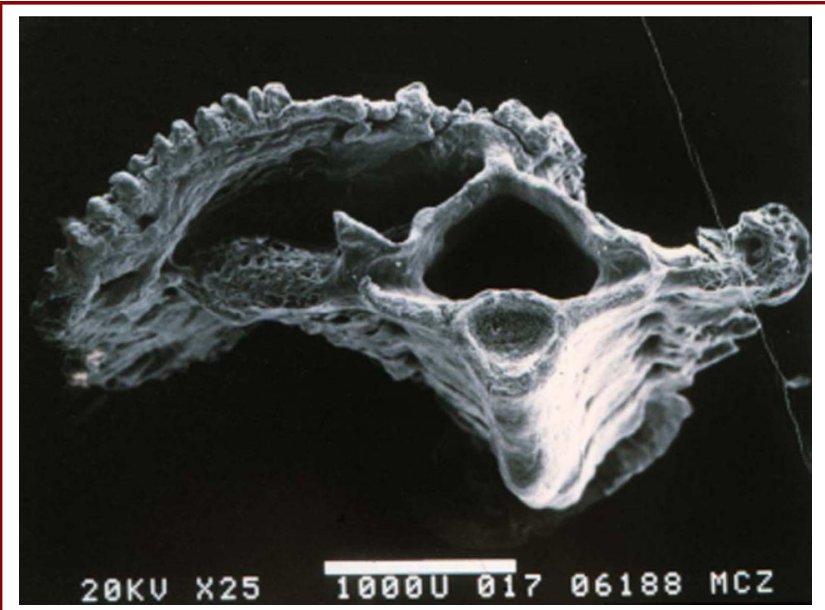

Figure 2. SEM of the axial skeleton of Brachycephalus (anterior view). The ossified dermal shield of this unusual frog is in contact and fused with the neural spines and the distal transverse processes of the trunk vertebrae. This is a convergent form of "carapace," though unknown to Carus at the time of his proposed Urtyp. Image from A.C. Burke. 
Pander, Karl Ernst von Baer, and Heinrich Rathke, all helped to define and expand the field of embryology and reduced the a priori, transcendental approach to morphology that Naturphilosophen such as Carus embraced (Churchill, '91). Most of these embryologists worked on accessible specimens, such as sea urchins, chickens, and mice, to understand laws and mechanisms driving the formation of new morphologies. And, although tortoises were difficult to obtain and to keep alive, some early embryologists and zoologists used them to refine and test their ideas about development as well as evolution. Most notably Martin Rathke and Richard Owen with their embryological investigations looked to the Chelonians for a fresh perspective on their work.

Rathke and Owen shared an epistemic commitment to understanding the development and diversity of organismal form through reference to embryological processes; however, their goals and conclusions about the turtle's shell were vastly different. Owen, unlike Rathke, was tied, like Cuvier, Geoffroy, and Carus, to a theory that could unite organismal form. For Owen, his archetype theory was the explanatory basis of all vertebrate diversity (although the mechanisms of producing diversity changed over time, as we shall see). This framework both drove his research, and colored his explanations of form-as we will see with his interpretation of the turtle's shell. Meanwhile, Rathke signifies a break with the tradition of grand theories of nature-his embryological investigations were in search of laws of development and thus mechanisms underlying common morphologies (Rathke, 1825). In this respect, Rathke is a precursor of important traditions in the history of embryology such as the later Entwicklungsmechanik (Churchill, '91).

Owen's and Rathke's studies represent a main epistemic shift in the investigation and understanding of turtle morphology. Whereas French functionalists, such as Cuvier, and structuralists, such as Geoffroy, as well as German Naturphilosophen such as Carus, had only looked into adult specimens and their anatomical features, the new embryologists shifted the explanatory focus to the fine understanding of the developmental mechanisms underpinning any morphology. This shift allowed them to test hypotheses of the relationships of parts and organisms, and is the basis upon which modern evo-devo studies are predicated. Most importantly, this shift also foreshadows current alternate views that emerge as a consequence of the differences in investigative style between paleontologists and developmental biologists about the nature and evolution of the turtle shell.

\section{Rathke's Comparative Embryology of Turtles}

While Karl Ernst von Baer may be the most well known of the proto-embryologists on the continent, Martin Rathke (17931860), a professor of zoology and anatomy at the University of Königsberg, is more rightly considered the founder of comparative embryology (Churchill, '91). Von Baer still embraced the transcendental principles of Naturphilosophie, and was concerned with generalizations in embryology and taxonomy (Churchill, '91). On the contrary, Rathke was a "humble observer" rather than a bold theorizer (Menz, 2000; 217)-his attention was on the details of individual development. According to Rathke, explaining a morphological trait meant following it throughout development and reconstructing the embryological processes that produced it (Menz, 2000). The impressive 1848 monograph "Über die Entwicklung der Schildkröten" dealing with the development of the turtle shell was borne out of the epistemic commitments of the new embryology: attention to the details and focus on embryological mechanisms underlying the emergence of any morphological trait. Rathke's 1848 text shifted the attention of turtle studies from anatomy to embryology. Following the publication of this work, it became clear that explaining the puzzling morphology of Chelonians could not rely on the anatomy of adult specimens, but had to address the underlying developmental mechanisms. As we will see, this approach drastically changed the field of Chelonian studies.

Like many scientists on the continent at the time, Rathke started his career under the influence of Naturphilosophie. However, only brief glimpses of this approach can be found in his works. In his early studies, such as "Beiträge zur Geschichte der Tierwelt" (1825), Rathke admitted that most ideas coming from natural philosophy were just dreams (Traumerei) that could inspire thinking and not metaphysical commitments about the real nature of the biological world. From the start, Rathke's works were largely focused on tracing through empirical observations, and in meticulous detail, the development of organisms. By tracing individual development, Rathke hoped to discover the laws, according to which different forms in nature emerge and take shape. Of the scientists covered thus far, Rathke is the first to truly embrace a mechanistic understanding of the constitution of form. His meticulous approach to chronicling the details of development led to immensely dense treatises, and also helped to establish the importance of looking to embryos and development to understand morphologies (Churchill, '91).

Rathke started his research on turtle embryonic development when he moved to Königsberg, by the Baltic Sea. He found that some lakes in southeastern Prussia supported thriving turtle populations. In a letter to his publisher, Friedrich Vieweg, Rathke described why he cared about turtles as well as why anybody interested in morphology should care about them (Menz, 2000). He explained that, although past masters of biology had acknowledged the importance of understanding turtles both because of their unusual morphology and because of their interesting place in the history of life on earth, scientists did not actually know much about turtle morphology. Rathke found a new way to fill this gap. He wrote "... research about the development of these animals will lead to more satisfactory explanations of their wondrous and puzzling body structure, than the ones we have produced so far by dissecting adult specimens" (Rathke, 1847, 756). In these words lies the shift from the anatomy to the embryology of turtle 
morphology. Rathke showed that, if scientists, wanted to explain how such a puzzling morphology comes about, they had to pay attention to its embryonic development. In an important passage referring to Carus's work on turtles, Rathke wrote: "Carus set up the above mentioned view [the mixed hypothesis] on the basis of studies of the skeletons of adult turtles: but such can not be held for sufficient, instead we need here further confirmation or correction by the developmental history (Rathke, 1848; 115)." Here Rathke clearly criticized Carus's ideas not just because they are incorrect. Rather he argues that Carus's approach, similar to the approach of all the other scientists who had investigated turtle morphology, was not adequate, as it was not informed by the mechanistic understanding of developmental processes.

Rathke published his first preliminary results on studies of embryonic turtles nearly 15 years after Carus developed the mixed hypothesis, in his 1846 short essay, "Vorläufingen Bemerkungen betreffend die Entwicklung der Schildkröten.” Years of experience impressed upon Rathke the difficulty of amassing sufficient evidence about embryonic development, and so, his efforts to find and grow turtle embryos were quite impressive. Von Baer, also an inhabitant of Königsberg at the time and a close friend of Rathke had already addressed the difficulties of obtaining specimens of tortoises (Von Baer, 1834; 546). Rathke first decided to get 100 eggs of Emys europea sent from other regions of Germany, as it was extremely difficult to obtain viable specimens in the Königsberg region (Menz, 2000). Such eggs, unfortunately, did not give rise to any embryos and all his attempts to have the eggs develop into embryos did not work, likely because of "stress" during transportation. Rathke then decided to have specimens sent from other countries-eventually yielding two viable embryos of Emys europaea. Eventually, in June 1847, Rathke finally obtained three recently laid eggs from different species: Testudo gracca; Chelonia midas, and E. europea. Using these three embryos, Rathke was finally able to observe development from the beginning to the middle time of their embryonic development, but no further, so more specimens were ordered to extend his investigation to more advanced stages.

In his embryological observations, Rathke found that no osseous plates developed independently in the corium that would coalesce afterward with the neural spines and ribs. According to him, the neural plates were expansions of the spinous processes of the vertebrae and the costal plates were extensions of the greater tubercle of the ribs (Rathke, 1848). Therefore, ribs and vertebrae build the carapace, and the carapace in combination with the scutes forms the external shield. In other words, according to Rathke, there are no osseous plates that develop independently in the dermis and afterward coalesce with the neural spines and ribs (Rathke, 1848). This is why he concluded that the carapace of Chelonians is composed exclusively of endoskeletal elements: "The spinous processes are already developed from the second to the eighth dorsal vertebrae before the exclusion of the embryo, [...] they remain pretty short, but contrary to the general laws of development of the vertebrate animals, they grow so much in breadth, that they form, after their ossification, a series of horizontal plates of moderate size" (1848). In his 1848 work, Rathke also held that the plastron has exoskeletal origins. He refers to the various parts of the plastron as "supplementary plates" and takes them for equivalent to the Nuchal, the Marginalia, and Pygalia in the Carapace.

In order to support his hypothesis about the endoskeletal nature of the carapace, in his 1848 monograph, Rathke made an unprecedented use of comparative analyses and is therefore also considered one of the founders of comparative embryology. In "Über die Entwicklung der Schildkröten," he wrote first about the "Characteristics of the Eggs" and first stages of development of the tortoise E. europea (Part 1). Then, he addressed developmental formation of the carapace in several kinds of turtles both from his observations and from previous studies, from E. europea to T. gracca, Chelonia virgata, and Tryonix aegiptiacus (Part 2). At the end, Rathke focused again on E. europea (Part 3). He showed that similarity in adulthood was not conclusive evidence of shared origins (Rathke, 1848; Agassiz, 1857). Among the firsts, Rathke emphasized the importance of understanding comparative embryology. The process of development for understanding evolutionary trajectories would become a major factor in the future of biology as well as in the study of turtle morphology (Goette, 1899).

\section{Owen's Archetypes and His Turtles}

While Rathke focused on detailing individual development over the creation of elaborate theories of nature's unity, Richard Owen (1804-1892), the man whose intensive works would establish the Natural History Museum in London, took a different stance. Throughout the 1840s, Owen established within his anatomical treatises an understanding of the unity of type that Geoffroy had embraced, lending his vast knowledge of the natural world to the creation of the archetype theory through inductive reasoning (Fig. 3). Owen's archetype, outlined in two major texts, On the Archetype and Homologies of the Vertebrate Skeleton in 1848 (Owen, 1848) (Owen had discussed the archetype in several earlier contexts, but did not fully explicate his theory in print until 1848), and On the Nature of Limbs in 1849, was highly influential to both the scholarly community and his own peripheral works, as we will see with the case of Owen's work on turtles. And, it is Owen's work on the archetype theory that ties him to the construction of grand theories of natural systems that his predecessors, like Cuvier, Geoffroy, and Carus, had attempted, but Rathke had rejected.

In late 1848, Owen submitted his manuscript, "On the Development and Homologies of the Carapace and Plastron of the Chelonian Reptiles" to the Royal Society of London. The text was read to the society in January of 1849. Owen's work on turtles, based off of careful dissections of at least six species of turtle, contrasts heavily with Rathke's both in terms of what he perceived 


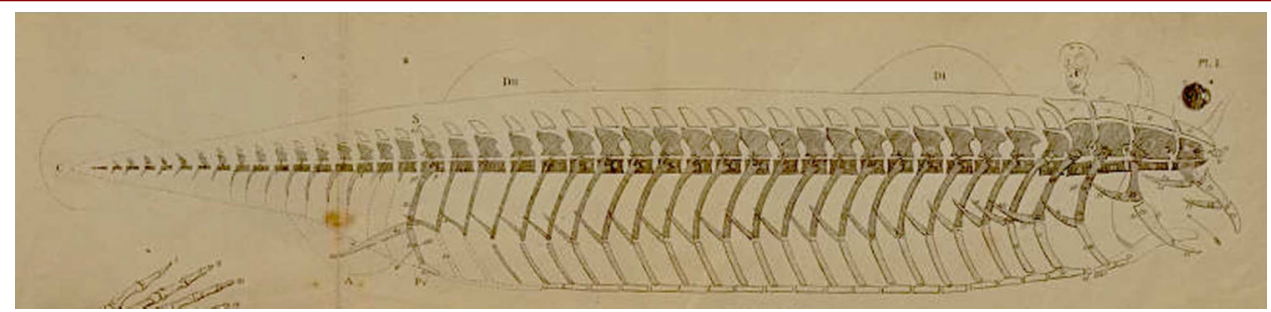

Figure 3. Owen's diagram of the simplest vertebrate skeleton, the Archetype. From Owen (1849b); Plate I, Figure 1.

to be the developmental origins of the carapace and plastron, and how he arrived at these conclusions.

By way of introduction to the issue of how the carapace and plastron develop, Owen offered his readers a review of previous works on the subject. From Geoffroy to Cuvier and Carus, Owen considered the theories of the turtle's shell and found the choice between any of them to be difficult to accept based upon the merits of their evidence, because they addressed a question of development with evidence gleaned from adult specimens. On this note, Owen tells us, "The guide to our choice of either of these [theories of carapace/plastron development], or of any other view that has been offered of the nature and signification of the thoracic-abdominal case of the Chelonia, must be the light afforded by a true perception and explanation of the phenomena of its development" (Owen, 1849a; 158). Thus, Owen sought his own evidence and explanation of shell development through embryology.

Through dissection and comparison of the embryos (and adults) of several species of turtles, Owen reached the conclusion that the carapace is a mixed structure-a finding reminiscent of Carus, but radically different in its inception. In his work, Owen looked at the development of the neural, costal, and marginal plates as separate phenomena. He identified eleven neural plates (this is in keeping with previous authors), and lumped the nuchal plate in with this classification. Neural plates 1-8 Owen saw as serial homologues, each beginning as what 0wen referred to as "dermal cartilage" (this term most likely refers to dermal connective tissue), but only becoming ossified once the neural spine of the subadjacent vertebra extended into the dermis. Thus, neural plates 1-8, according to Owen, were endoskeletal, because their ossification was an extension of the underlying vertebrae. Meanwhile, neural plates 9-11 and the nuchal bone, also began as dermal cartilage, but continued their development as independent centers of ossification. Because, Owen reckoned, these plates do not ankylose with the vertebral spines, they must be considered dermal bone, like that of a crocodile, and are thus exoskeletal.

While Owen thought the neural plates to be mixed in their composition, he saw the costal plates as purely endoskeletal. These plates began as dermal cartilage, and became ossified as the process spread from near the head of the underlying rib into the costal plate. While the diagnosis of endoskeletal costal plates is in agreement with the views of Rathke, the mechanism through which the ossification occurs was different enough for Owen to spend a great deal of time to explain. To Rathke, the costal plates could be considered as outgrowths of the greater tubercle of the ribs, just as the neural plates could be considered as expansions of the spinous processes of the vertebrae. To Owen, however, the plates could not develop simply as outgrowths of ribs for the following reasons: (1) the placement of the costal plates over the ribs is variable (in fact, he found that the placement of the plates was more closely aligned with the development of the scutes), and (2) within the vertebrates, the greater tubercle of the ribs is not variably placed (i.e., it always develops from the true neck of the rib). It follows that if the placement of the tubercle is invariable, but the placement of the plate over the tubercle is variable, then the plate is not a simple outgrowth of the tubercle. Thus, Owen and Rathke agreed on the developmental origins of the costal plates, but not on the mechanism of their development.

When it came to the issue of the plastron, Owen's interpretation, based on dissections of embryonic tortoises and adult Trionyx specimens led him to the conclusion that the plastron is an endoskeletal structure (Fig. 4)-a finding that directly contradicted Rathke's exoskeletal determination. Additionally, Owen saw evidence in the development of the tortoise to hypothesize that the nine pieces of the plastron are modifications of the sternum (entosternum [s] and episternals [es]) and the haemapophyses (hyosternals [hs], hyposternals [ps], and xiphisternals [xs]) found within the larger vertebrate clade. Owen's finding of homology between the plastron and the sternum resonates with the determination of Cuvier (1799, 1819) and Geoffroy-St-Hilaire (1809), but Cuvier and Geoffroy had not made the comparison of some of the plastral plates to the haemapophyses (sternal ribs/ costal cartilage). Burke ('89) has claimed that “Owen's interpretation of the plastron was influenced by his own theory of the archetypal vertebral segment, and he homologized the plastral bones with thoracic haemapophyses ... (Burke, '89; 364)" which is a point that bears further discussion here.

Taking a closer look at Owen's archetype concept, recall the previous discussion of Carus' Urtyp from 1828-0wen borrowed heavily from Carus to develop his own archetype (although he was 


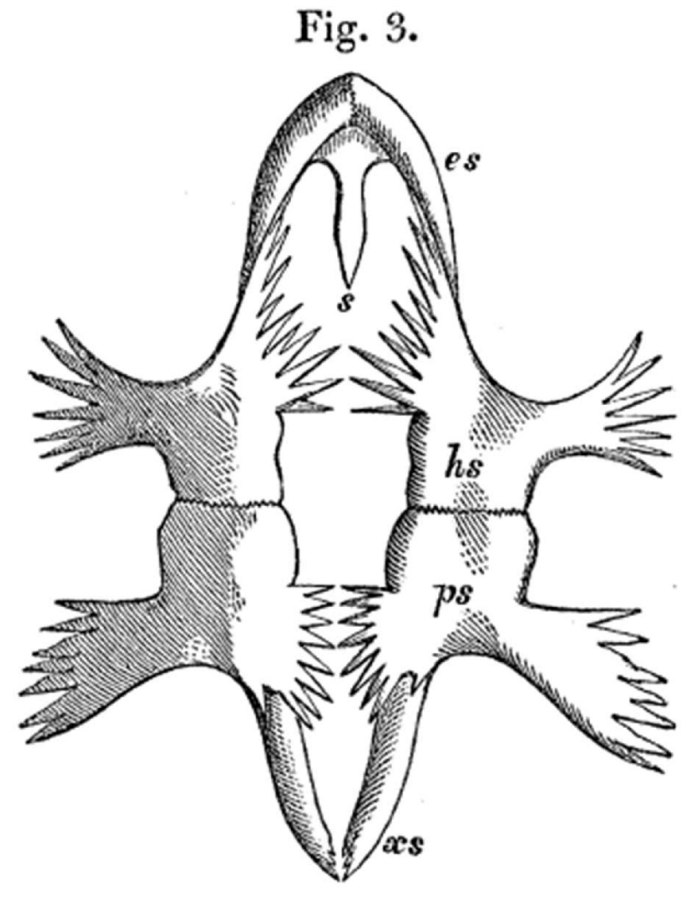

Plastron of Chelone caouanna.

Figure 4. Owen's diagram of plastron of Chelone caouanne (modern day Caretta caretta). From Owen (1849a); Figure 3, pg. 153. es = episternal, $s=$ sternal, hs = hyosternal, $\mathrm{ps}=$ hyposternal, $\mathrm{xs}=$ xiphisternal.

wont to admit it). Owen, much like Carus, considered the archetype to be the most elementary form of vertebrate. The data, or evidence, upon which Owen built his archetype was similar to the epistemology proposed by Geoffroy-that of homologies (what Geoffroy had referred to as "analogies"). The principle of homology (a term that Owen coined, and which helped to standardize the anatomical lexicon) meant that the significance of an organ or structure was derived from its place in the make-up of the whole organism (recall Geoffroy's "Principle of Connections"). This structuralist understanding of anatomy stood at odds with the functionalist view that dominated some of the scientific and social circles in which Owen was embedded in England. These circles, most notably scholars at 0xbridge, like Adam Sedgwick and William Whewell, grew increasingly wary of Owen's homological program, even though his inductive approach to anatomy gave transcendental morphology a systematic basis that it had thus far lacked (Rupke, '94).

The transcendental turn of Owen's comparative anatomy, coupled with his embracing the archetype as an idealized generalization (and not an actual entity) strained his relations with 0xbridge scholars during the late 1840s, such that, by the time his On the Nature of Limbs came out in 1849 (1 year after the archetype text), Owen had reversed his stance on the archetype. Whereas previously, and in keeping with the Naturphilosophen, Owen viewed the archetype as the result of a material force that propelled nature to differentiate, by 1849 , he expounded the archetype as a metaphysical entity that was the blueprint for the formation of animal life (Rupke, '93). This new vision of the archetype is evidenced by his reference to it as a "predetermined pattern" in On the Nature of Limbs (Owen, 1849b; 2). This new instantiation made Owen's archetype concept teleological, and although Owen continued his research in a mostly structuralist vein, his reincarnation of the archetype put that concept in line with both the Oxbridge functionalist's and Cuvier's highly teleological worldview.

This volte-face has interesting implications for the context of Owen's work on turtles. To begin, Owen's turtle treatise is sandwiched in time between his two texts on the archetype, and contains evidence of his pull from both sides (structuralism and functionalism). At first, we see Owen giving evidence against a functional interpretation of the carapace, “... their presence [the costal plates] seems to be determined rather by the angle of the union of the superincumbent vertebral scutella with the lateral or costal scutella, than by the necessity for additional strength in the articulation of the ribs with the spine (Owen, 1849a; 162)." Here Owen refers to the previous discussion of the placement of the costal plates-which he sees as being more closely aligned with the development of the overlying scutes than with the underlying ribs. Despite this, Owen also employs functionalist interpretations: "The main purpose of the augmentation of the ordinary vertebral elements in the thoracic-abdominal region of the Chelonia, by the extension of ossification from them into the corium, and the consequent connation with those elements of dermal bony plates, being the formation of a strong defensive abode ..." (Owen, 1849a; 165) [Emphasis is ours]. This passage shows that at the time of writing his turtle treatise, Owen's interpretations were caught-up in the transition that his own archetype concept was makingfrom structuralist and transcendental, where the cause of structural differentiation from the archetype was the presence of a material force, towards teleological explanations, where structures are explained by the purpose they serve.

Owen's commitment to the archetype concept may have colored his interpretation of his evidence regarding the issue of the plastron. Although Owen adopted a different methodology and forms of evidence than Cuvier, Geoffroy, and Carus, his works were driven, much like theirs, by an underlying theory of natural unity and the requirement that all nature somehow fit this unity. While his turtle treatise is not an overt overture to the archetype theory, the treatise is firmly entrenched within that theory. Owen bases the interpretation of his evidence on an understanding that the turtle's morphology must be a modification of a more basal plan, as evidenced in the following quote: 
The most obvious, and, I believe, the most natural explanation of this first complete segment of the thoracicabdominal region of the young Tortoise, according to the typical vertebra, and the composition of the corresponding segment in the nearest allied Vertebrata, is-that the centrum, the neural arch, and the pleurapophysis, are parts so indicated by the initial letters; that the hyosternals are the haemapophyses (sternal ribs or costal cartilages), and the entosternum is the 'haemal spine' or sternum proper (Owen, 1849a; 163).

In this quote, Owen is telling his reader that the only way to account for the turtle's peculiar morphology is to envision that some parts-namely those of the plastron-are extensively modified homologues of extant vertebrate parts. In this theoretical scheme, the entire turtle body plan can be thought of as a revised form of the archetypal vertebrate, and it is this systematic comparison and understanding of modification from a simple, shared vertebrate structure, that drives Owen's understanding of the natural system and interpretation of evidence.

\section{CONCLUSION: RATHKE, OWEN, AND THE RISE OF EMBRYOLOGY}

The immense importance that Rathke and Owen had placed upon embryology was embraced by many subsequent authors (see, for instance, Darwin's chapter 13 of On the Origin of Species). To many, embryology became the main source of evidence for classification and understanding the natural order. This upsurge in popularity was due in part to Rathke's discovery that the limitations of homology must be understood through embryology. The homology concept, which was at the core of Geoffroy's epistemology, but was probably best expressed within the work of Owen, thus became tied to embryology and understanding developmental transformations. According to Darwin, for instance, “... in the eyes of most naturalists, the structure of the embryo is even more important for classification than that of the adult."

The methods used by the progenitors of turtle studies, from the comparative analysis of adult specimens to comparative embryology and the production of mechanistic hypotheses, have influenced contemporary studies by workers in phylogenetic systematics who seek not only to resolve turtle origins and relations, but also to make hypotheses regarding the homology of the bones of the turtle shell. Current evo-devo investigations are continuing to hypothesize about the relationships between the various elements of the turtle shell. Details of the cellular origin of all the elements will provide a stable vocabulary for future comparative studies. As of now the difficulties of embryonic fate mapping in this system leave many questions unresolved.

The monophyly of turtles has never been questioned (e.g., Gaffney, '84), but the origin of turtles within Reptilia has remained elusive, with the various morphological hypotheses of phyloge- netic affiliation being contingent upon how one interprets the shell (Reisz and Laurin, '91; Lee, 1993, '96, '97; Laurin and Reisz, '95; DeBraga and Rieppel, '97; Rieppel and Reisz, '99; Hirasawa et al., 2013; Lyson et al., 2013b). Data from molecular analyses have been accumulating for decades, and now lean heavily toward positioning turtles as diapsids and as the sistergroup to Archosaurs (Shaffer et al., 2013; Wang et al., 2013). Further data and analyses might change this view, but ironically these approximations of the root of the tree among extant taxa will not significantly change the remaining questions about the evolution of the shell. Resolving the origin of the turtle shell to the satisfaction of all will require new discoveries in the fossil record along with synthesis of evidence from morphological, developmental, and molecular biologists.

\section{ACKNOWLEDGMENTS}

The authors would like to thank the faculty and staff at the Center for Biology and Society, Arizona State University, for their support, as well as the Fulbright Foundation, funding from which precipitated the earliest discussions of this article. Funding for JEMV was provided by the Academy of Finland.

\section{LITERATURE CITED}

Agassiz L. 1857. Contributions to the natural history of the United States of America. Boston: Little, Brown and Company.

Amundson R. 2005. The changing role of the embryo in evolutionary thought: roots of evo-devo. Cambridge, UK: Cambridge University Press.

Appel T. 1987. The Cuvier-Geoffroy debate: French biology in the decades before Darwin. New York: Oxford University Press.

Burke AC. 1989. Development of the turtle carapace: implications for the evolution of a novel bauplan. J Morphol 199:363-378.

Carus CG. 1827. An introduction to the comparative anatomy of animals, tr. by RT Gore. 2 vols. [and] Plates.

Carus CG. 1828. Von den Ur-Theilen des Knochen-und Schalengerüstes.-Leipzig, Gerhard Fleischer 1828. Gerhard Fleischer.

Cebra-Thomas J, Tan F, Sistla S, et al. 2005. How the turtle forms its shell: a paracrine hypothesis of carapace formation. J Exp Zool Part B 304:558-569.

Churchill, FB. 1991. The rise of classical descriptive embryology. In: A conceptual history of modern embryology. Springer US, 1991. 1-29.

Cuvier G. 1800-1805. Leçons d'anatomie comparée. Paris: Baudouin. p 5.

Cuvier GB, Mudie R, Johnston G, Westwood J0, Carpenter WB. 1854. The animal kingdom: arranged after its organization, forming a natural history of animals, and an introduction to comparative anatomy. London: WS Orr and Company.

DeBraga M, Rieppel 0. 1997. Reptile phylogeny and the interrelationships of turtles. Zool J Linnean Soc 120:281-354.

Gaffney ES. 1984. Historical analysis of theories of chelonian relationship. Syst Biol 33:283-301.

Geoffroy-St-Hilaire M. 1809. Mémoire sur les tortues molles. Bulletin des Sciences, par la Société Philomatique de Paris, 363-367. 
Gilbert SF, Loredo GA, Brukman A, Burke AC. 2001. Morphogenesis of the turtle shell: the development of a novel structure in tetrapod evolution. Evol Dev 3:47-58.

Goette A. 1899. Über die Entvicklung des knöchernen Rückenschildes (Carapax) der Schildkröten, Z. wiss. Zool. Bd 66.

Hirasawa T, Nagashima H, Kuratani S. 2013. The endoskeletal origin of the turtle carapace. Nat Commun 4:2107.

Laurin M, Reisz RR. 1995. A reevaluation of early amniote phylogeny. Zool J Linnean Soc 113:165-223.

Lee MS. 1993. The origin of the turtle body plan: bridging a famous morphological gap. Science 261:1716-1720.

Lee MS. 1996. Correlated progression and the origin of turtles. Nature 379:812-815

Lee MSY. 1997. Pareiasaur phylogeny and the origin of turtles. Zool J Linnean Soc 120:197-280.

Lenoir T. 1981. The Göttingen School and the development of transcendental Naturphilosophie in the Romantic Era. Stud Hist Biol 5:111-205

Lyson TR, Bhullar BAS, Bever GS, et al. 2013a. Homology of the enigmatic nuchal bone reveals novel reorganization of the shoulder girdle in the evolution of the turtle shell. Evol Dev 15:317-325.

Lyson TR, Bever GS, Scheyer TM, Hsiang AY, Gauthier JA. 2013b. Evolutionary origin of the turtle shell. Curr Biol 23:1113-1119.

Menz H. 2000. Martin Heinrich Rathke (1793-1860): Ein Embryologe des 19. Jahrhunderts, Acta Biohistorica, 7. Marburg: BasiliskenPresse.

Moustakas JE. 2008. Development of the carapacial ridge: implications for the evolution of genetic networks in turtle shell development. Evol Dev 10:29-36.

Owen R. 1848. On the archetype and homologies of the vertebrate skeleton. London: John van Voorst, Paternoster Row.

Owen R. 1849a. On the development and homologies of the carapace and plastron of the chelonian reptiles. Philos Trans $\mathrm{R}$ Soc Lond 139:151-171.

Owen R. 1849b. On the nature of limbs: a discourse delivered on Friday, February 9, at an evening meeting of the Royal Institution of Great Britain. London: John Van Voorst.

Rathke H. 1825. Beiträge zur Geschichte der Thierwelt. Dritte Abtheilung der Schriften der Naturforschenden Gesellschaft zu
Danzig. Viertes Heft. Halle: In der Rengerschen VerlagsBuchhandlung.

Rathke H. To Vieweg, Friedrich. 22 September 1847. Folder 1255, Herzog-August-Bibliothek.

Rathke H. 1848. Über die Entwicklung der Schildkröten. Braunschweig: Friedrich Vieweg und Sohn.

Reisz RR, Laurin M. 1991. Owenetta and the origin of turtles. Nature 349:324-326.

Rieppel 0. 2013. The evolution of the turtle shell. In Morphology and evolution of turtles. Netherlands: Springer. p 51-61.

Rieppel 0, Reisz RR. 1999. The origin and early evolution of turtles. Annu Rev Ecol Syst 1-22.

Rudwick MJ. 2008. Georges Cuvier, fossil bones, and geological catastrophes: new translations and interpretations of the primary texts. Chicago: University of Chicago Press.

Rupke NA. 1993. Richard Owen's vertebrate archetype. Isis 84: 231-251.

Rupke NA. 1994. Richard Owen: Victorian naturalist. New Haven: Yale University Press. p 48-55.

Scheyer TM, Martin Sander P, Joyce WG, Böhme W, Witzel U. 2007. A plywood structure in the shell of fossil and living soft-shelled turtles (Trionychidae) and its evolutionary implications. Organ Divers Evol 7:136-144.

Scheyer TM, Brullmann B, Sanchez-Villagra MR. 2008. The ontogeny of the shell in side-necked turtles, with emphasis on the homologies of costal and neural bones. J Morphol 269:1008-1021.

Shaffer HB, Minx P, Warren DE, et al. 2013. The western painted turtle genome, a model for the evolution of extreme physiological adaptations in a slowly evolving lineage. Genome Biol 14:R28.

Von Baer KE. 1834. Beitrag zu der Entwickelungsgeschichte der Schildkröten. Arch Anat Physiol 544-550.

Wang Z, Pascual-Anaya J, Zadissa A, et al. 2013. The draft genomes of soft-shell turtle and green sea turtle yield insights into the development and evolution of the turtle-specific body plan. Nat Genet 45:701-706.

Winsor MP. 1976. Starfish, jellyfish, and the order of life. New Haven: Yale University Press.

Zangerl R. 1939. The homology of the shell elements in turtles. J Morphol 65:383-409. 